\title{
Neuroendocrine changes after aneurysmal subarachnoid haemorrhage
}

\author{
Zuleyha Karaca $^{1}$. Aysa Hacioglu' ${ }^{1}$ [ $\cdot$ Fahrettin Kelestimur ${ }^{2}$
}

Published online: 14 January 2019

(c) Springer Science+Business Media, LLC, part of Springer Nature 2019

\begin{abstract}
Introduction The prevalence of pituitary dysfunction is high following aneurysmal subarachnoid hemorrhage (aSAH) and when occurs it may contribute to residual symptoms of aSAH such as decreased cognition and quality of life. Hypopituitarism following aSAH may have non-specific, subtle symptoms and potentially serious consequences if remained undiagnosed. Methods We reviewed the literature on epidemiology, pathophysiology, diagnostic methods and management of neuroendocrine changes after aSAH as well as on the impact of pituitary dysfunction on outcome of the patient.

Results The prevalence rates of pituitary dysfunction after aSAH varies greatly across studies due to different diagnostic methods, though growth hormone deficiency is generally the most frequently reported followed by adrenocorticotropic hormone, gonadotropin and thyroid stimulating hormone deficiencies. Pituitary deficiency tends to improve over time after aSAH but new onset deficiencies in chronic phase may also occur. There are no clinical parameters to predict the presence of hypopituitarism after aSAH. Age of the patient and surgical procedures are risk factors associated with development of hypopituitarism but the effect of pituitary dysfunction on outcome of the patient is not clear. Replacement of hypocortisolemia and hypothyroidism is essential but treatment of other hormonal insufficiencies should be individualized.

Conclusions Hypopituitarism following aSAH necessitates screening despite lack of gold standard evaluation tests and cutoff values in the follow up, because missed diagnosis may lead to untoward consequences.
\end{abstract}

Keywords Aneurysmal subarachnoid haemorrhage $\cdot$ Hypopituitarism $\cdot$ Neuroendocrine dysfunction $\cdot$ Diabetes insipidus

\section{Introduction}

Aneurysmal subarachnoid haemorrhage (aSAH) occurs with an incidence of 6-10/100,000 per year [1] with an age predilection of $40-60$ years. The 6-months mortality rate is about $50 \%$. The progress in neurosurgical, endovascular and neurointensive care unit facilities led to an increase in the number of survivors of patients with aSAH [2]. However, aSAH has major social, functional and economic implications since it affects patients in their most reproductive years.

Neuroendocrine dysfunction may be one of the contributing factors for residual symptoms after aSAH such as decreased cognition and quality of life [3-5]. In a recent

Zuleyha Karaca

zuleyha@erciyes.edu.tr

1 Department of Endocrinology and Metabolism, Erciyes University Medical School, Kayseri, Turkey

2 Department of Endocrinology and Metabolism, Yeditepe University Medical School, Istanbul, Turkey meta-analysis, the prevalence of pituitary dysfunction was found to be high suggesting the necessity for screening protocols for both acute and long-term follow-up to select patients requiring more detailed investigation [6].

The cognitive and functional deficits observed after aSAH resemble to the non-specific symptoms of hypopituitarism which might be missed easily and might have serious, sometimes life threatening consequences in affected patients.

\section{Epidemiology of pituitary dysfunction in aSAH}

Symptomatic hypopituitarism was first reported as a late complication of aSAH in three cases in 1961 [7]. The first structured study in 1969 showed abnormal diurnal variation of plasma cortisol in $65 \%$ and subnormal urinary steroid response after metyrapone in $44 \%$ of cases with aSAH [8]. There is considerable variation in later studies evaluating the prevalence of pituitary dysfunction after aSAH. 
Hypopituitarism affecting at least one of the pituitary axis after aSAH was reported at rates of 37-55\% [3, 5, 9-11]. The pooled prevalence of hypopituitarism in general was found to be $47 \%$ (95\% confidence interval $=37-57 \%$ ) in an early metaanalysis [12]. Table 1 summarizes the studies showing the prevalence of pituitary dysfunction in patients with aSAH (Table 1).

Most studies consistently show relative preponderance of growth hormone (GH) deficiency (GHD) after aSAH followed by adrenocorticotropic hormone (ACTH), gonadotropin and thyroid stimulating hormone (TSH) deficiency [30, $33,34]$. In the acute phase of aSAH, gonadotropin levels are usually low which recover in the long term follow-up. A mild degree of hyperprolactinemia may also be seen that resolve in a few months time [5]. Kopczak et al. investigated 509 patients with brain injury (169 of them with aSAH) in a neurorehabilitation center $<1$ month after the event. Among aSAH patients $30.1 \%$ of men without concomitant hyperprolactinemia showed decreased testosterone values. Hypogonadism was detected in $19.1 \%$ of all men $(\mathrm{T}<230 \mathrm{ng} / \mathrm{dL})$ [25]. However, the study was designed to test the efficiency of a screening program, therefore no confirmatory tests were performed.

In a recent metaanalysis, the time point of evaluation was demonstrated to influence the frequency of pituitary dysfunction after aSAH. The prevalence of any type of hypopituitarism was shown to decrease over time, ranging from $31 \%$ (95\% CI $0.22-0.43$ ) at 3-6 months to $25 \%$ (95\% CI $0.16-0.36$ ) at 6 months [33]. A trend of improvement in hypogonadotropic hypogonadism, diabetes insipidus, and multiple hormone deficiencies by time, which was statistically not significant was reported. The prevalence of secondary adrenal insufficiency and secondary hypothyroidism remained unchanged and GHD persisted in the long-term with an increasing trend of deterioration [33]. A prospective study of $100 \mathrm{aSAH}$ patients revealed $14 \%$ of hypocortisolism in the acute setting according to basal cortisol levels. However only 5\% had ACTH deficiency and 10\% GHD with dynamic testing in the long-term [35].

Robba et al. in their metaanalysis defined the acute phase of the aSAH as the first 6 months after the event and the chronic phase as the period after 6 months [6]. Overall prevalence of altered basal hormone levels was found to be $36.4 \%$ (95\% CI 23.7-51.3). The pooled prevalence of abnormal stimulation tests were $29 \%$ (95\% CI 18.7-42.2). The prevalence of pituitary dysfunction in the acute phase was 49.3\% (95\% CI 41.6-56.9) and 25.6\% (95\% CI 18.0-35.1) in the chronic phase. Single pituitary hormone dysregulation in total was found to be much higher than multiple pituitary hormone deficiencies.

The results showing prevalences of pituitary dysfunction in three metaanalyses were compatible with each other. Nearly half of the patients in the early phase of aSAH and a quarter of patients in the chronic phase harbor pituitary dysfunction $[6,12,33]$. These metaanalyses share the limitations of original studies and there is a high heterogeneity in the prevalence rates. The heterogenous results in the studies can be explained by time points and methods of assessment, inclusion and exclusion criteria and management method of aneurysm applied. Although there is a trend of improvement in pituitary dysfunction by time [6], some studies have shown new onset deficiencies in the chronic phase of aSAH also [20, 22, 30,36].

An important factor affecting the prevalence of hormone deficiency is the diagnostic method and cut-offs used to assess the pituitary functions. Somatotrophic axis has been evaluated by serum IGF-1 in some studies [5, 16, 20], GHRH-arginine test in some [3,10,14, 17, 27], insulin tolerance test (ITT) $[13,17,26,35]$ or glucagon stimulation test (GST) [22, 35, 37]. The detected rate of GHD was the highest with GHRHarginine test among all tests (25\%). Studies that used higher cut-off levels $(<9 \mu \mathrm{g} / \mathrm{L})$ of $\mathrm{GH}$ led to higher prevalence of GHD than studies which used lower cut-off levels $(<8 \mu \mathrm{g} / \mathrm{L})$. The reported frequency of GHD was lowest with ITT (15\%) (cut-off level used was $3 \mu \mathrm{g} / \mathrm{L}$ in all studies). For the GST cutoffs used were $1.18 \mu \mathrm{g} / \mathrm{L}$ and $3 \mu \mathrm{g} / \mathrm{L}$ for GHD and reported pooled frequency was $23 \%$ [9].

Hypothalamic-pituitary-adrenal (HPA) axis was evaluated by basal cortisol level $[9,10,21]$, ACTH stimulation test (low [5] and standard dose [17, 27, 35]) and GST [3, 35, 37]. The pooled prevalence of adrenal insufficiency was lowest (5\%) with basal cortisol measurement, $10 \%$ with ACTH test, $16 \%$ with ITT and highest (22\%) with GST. Cut-offs used directly affected the frequencies, when higher cut-offs were used frequency of adrenal insufficiency increased and when lower cutoffs were used frequency of adrenal insufficiency decreased [9].

Secondary hypothyroidism was usually evaluated with free thyroxine and TSH levels, TRH stimulation test and T3 resin uptake was used in only one study [17]. The pooled prevalence of secondary hypothyroidism was $4 \%$ [9].

Hypogonadotropic hypogonadism had a pooled frequency of $11 \%$ [9]. Prolactin levels were found to be low in general, however mild hyperprolactinemia was seen in some of the studies (Table 1).

Hypopituitarism seems to be a common complication of hypopituitarism. The reported prevalence rates vary considerably due to different dynamic tests and cut-offs used in the studies. However, due to potentially harmful consequences of missed diagnosis of hypopituitarism, screening should be carried out despite lack of gold standard evaluation tests and cut-off values. 


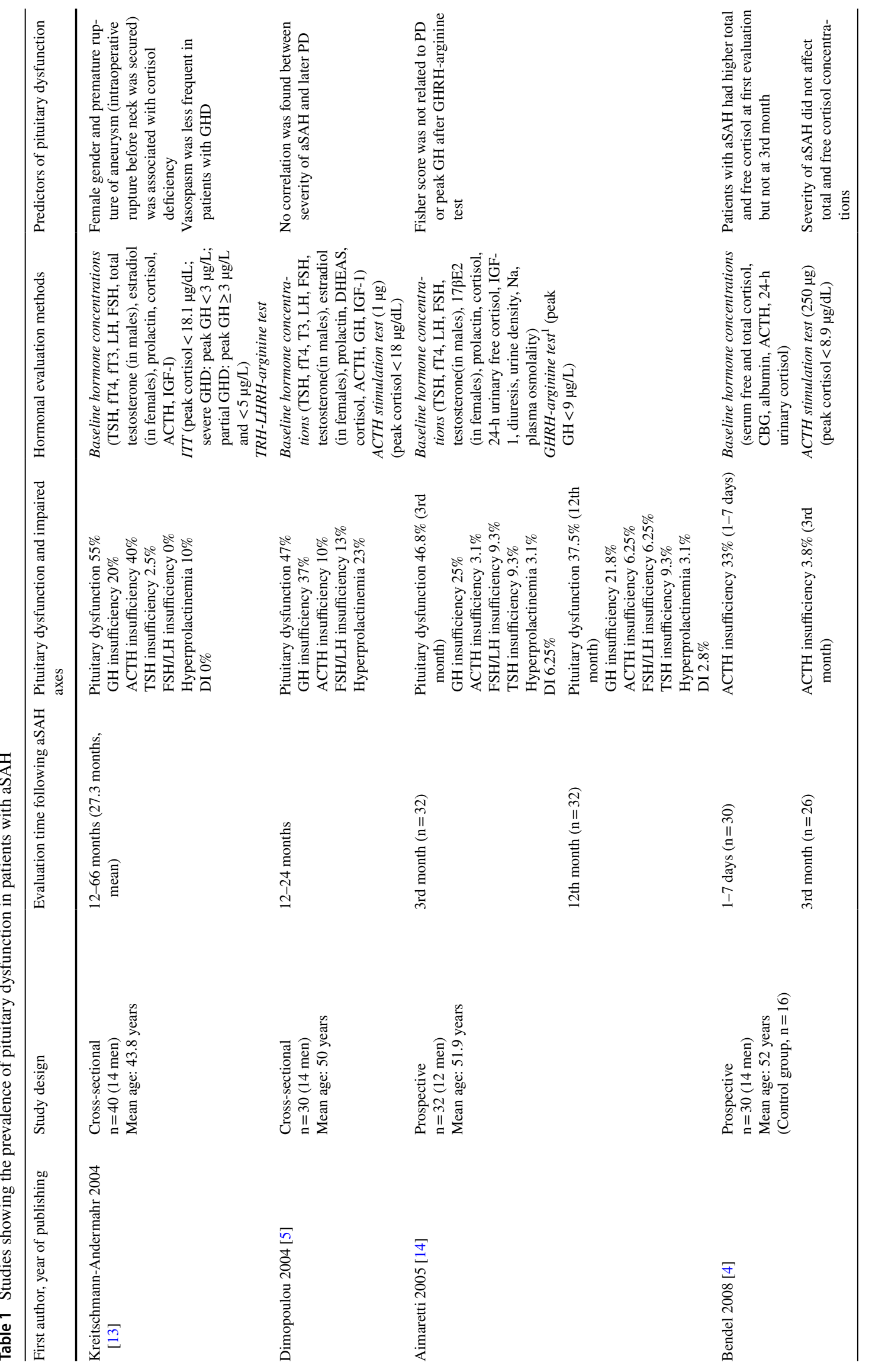




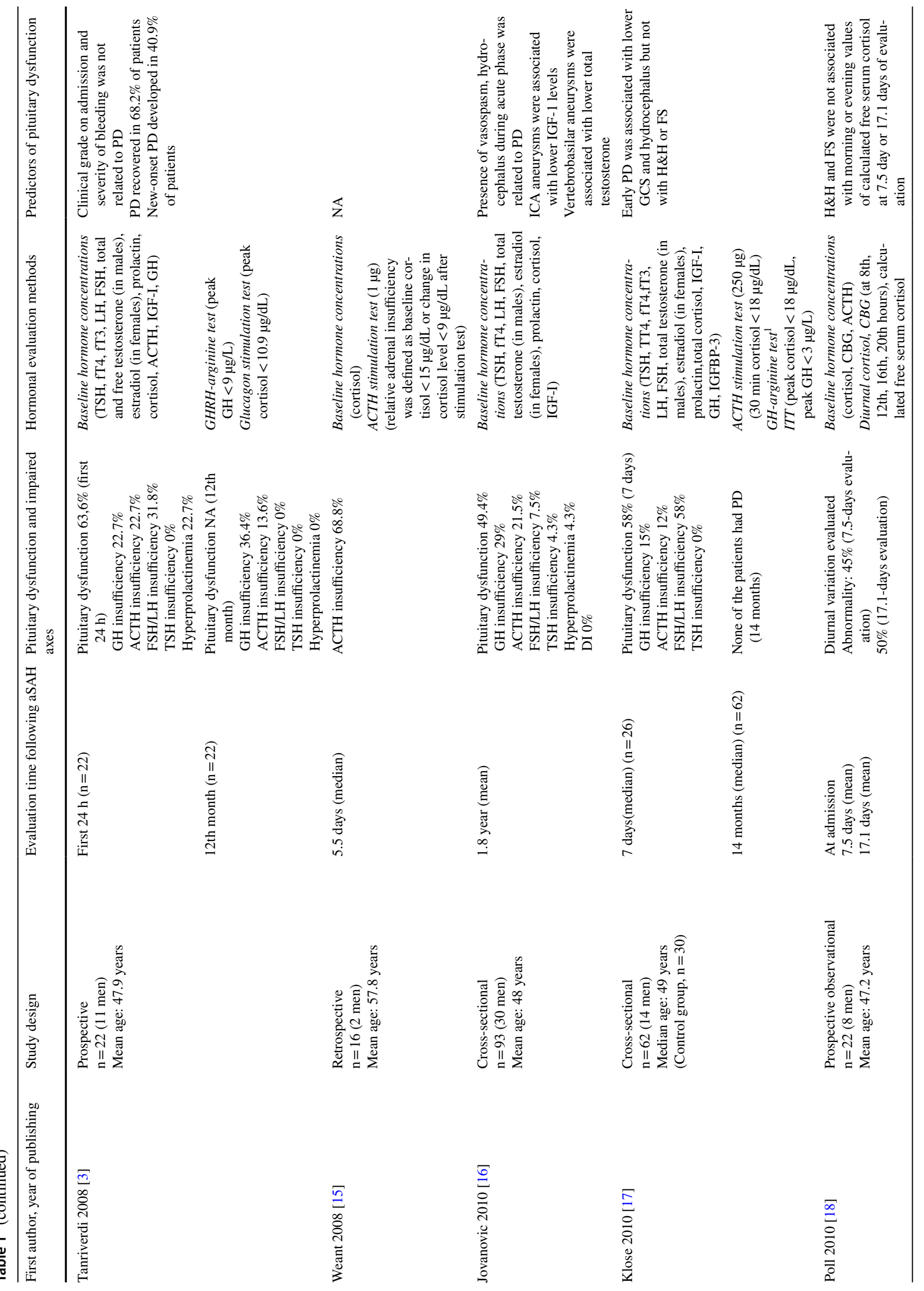




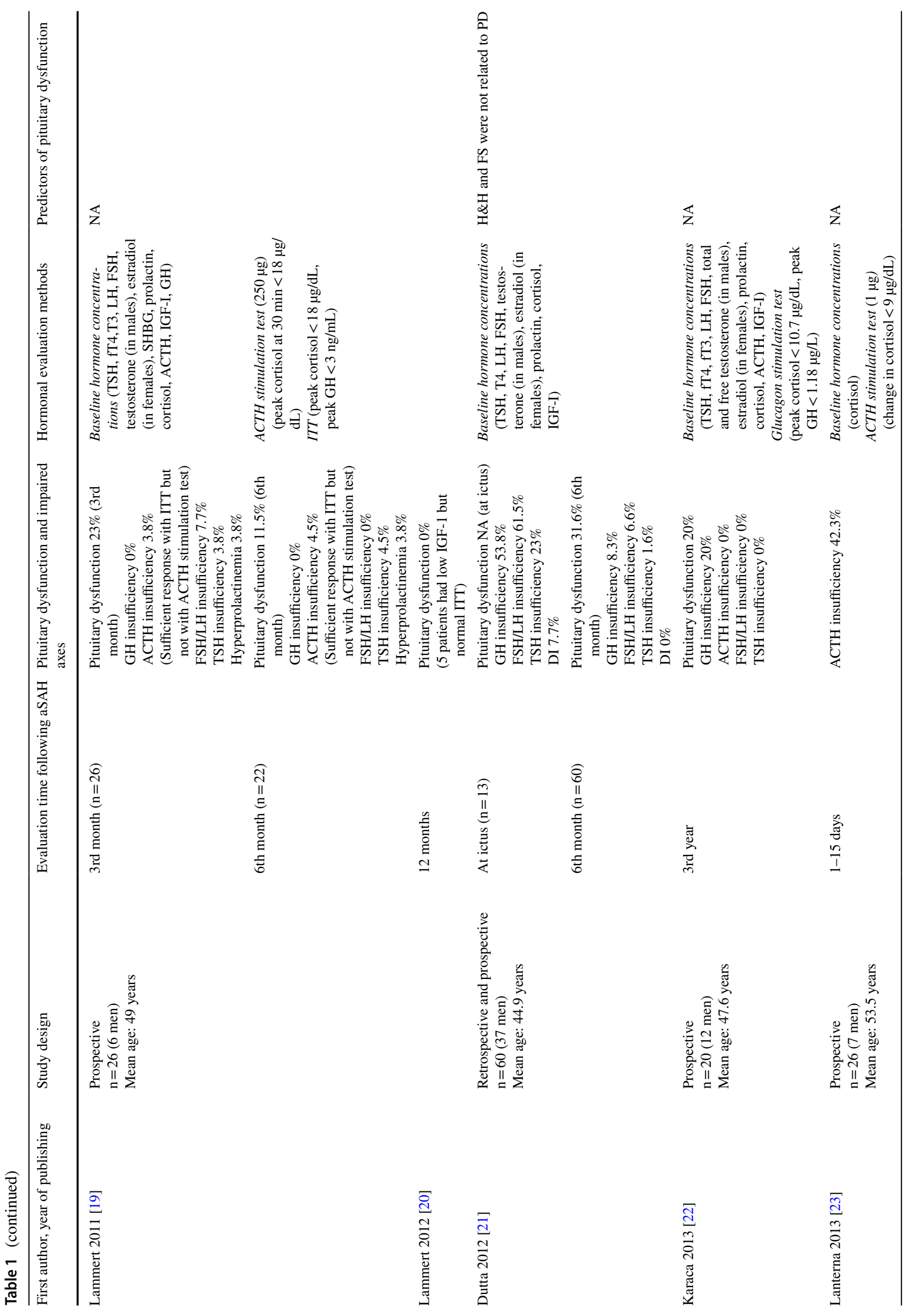




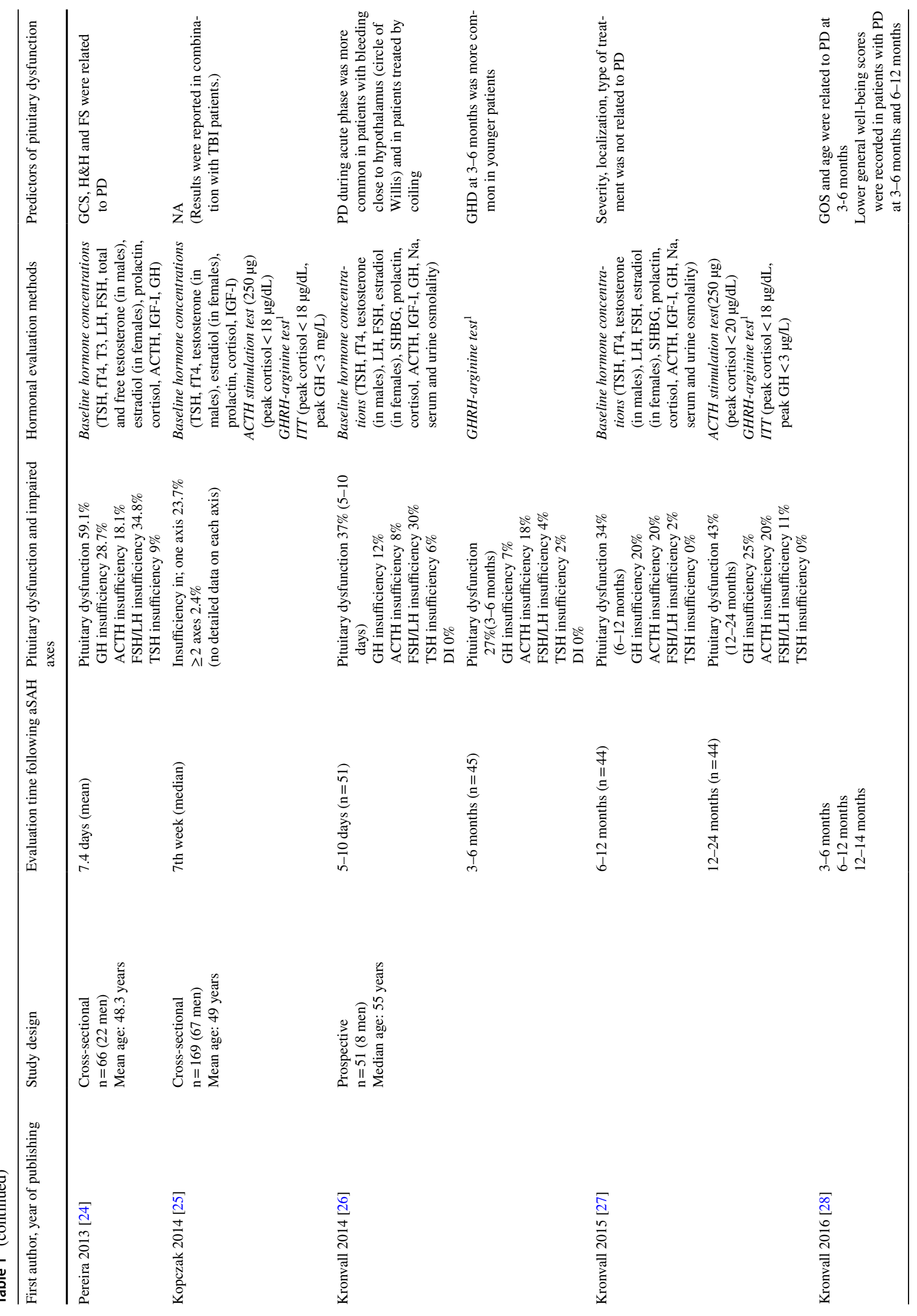




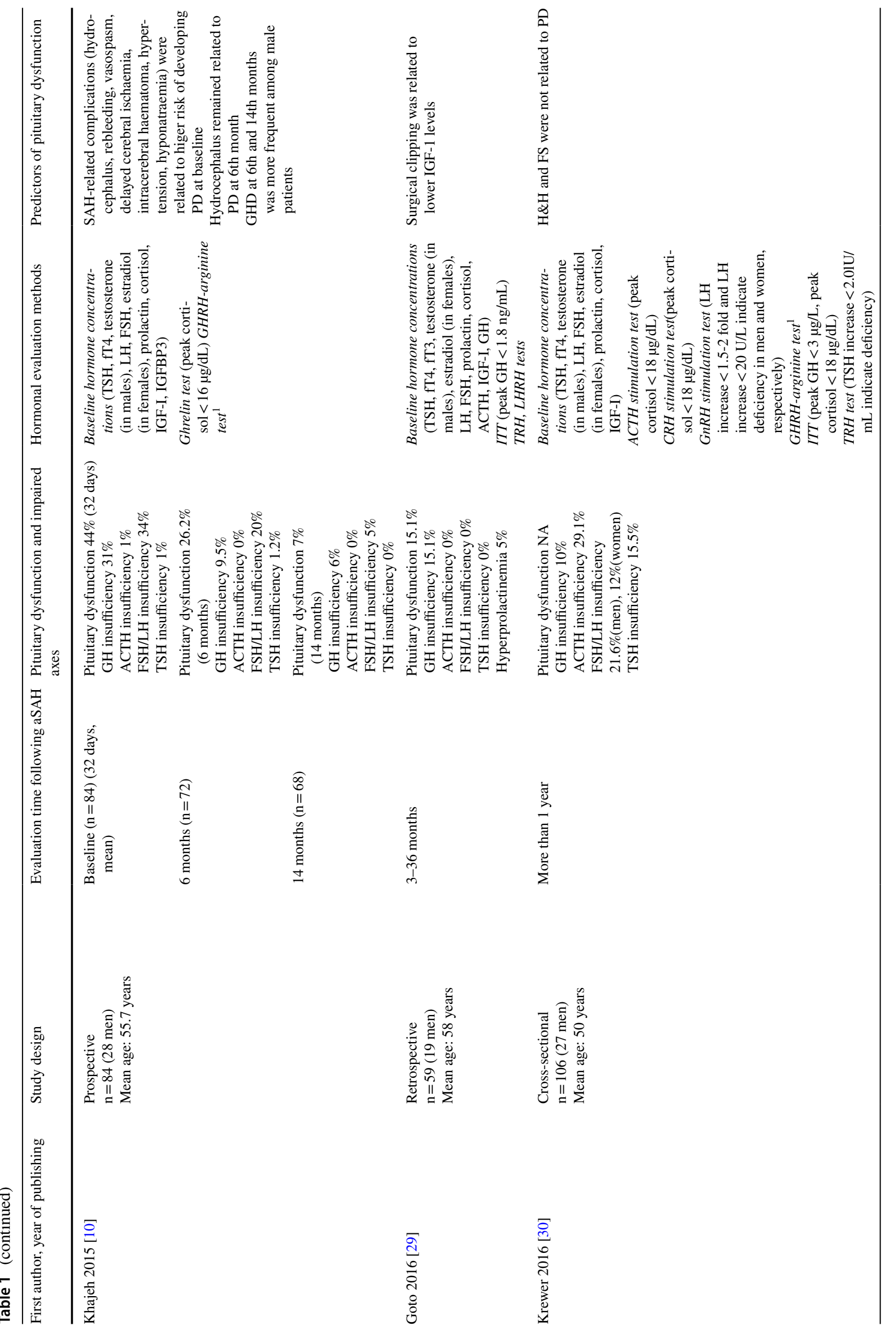




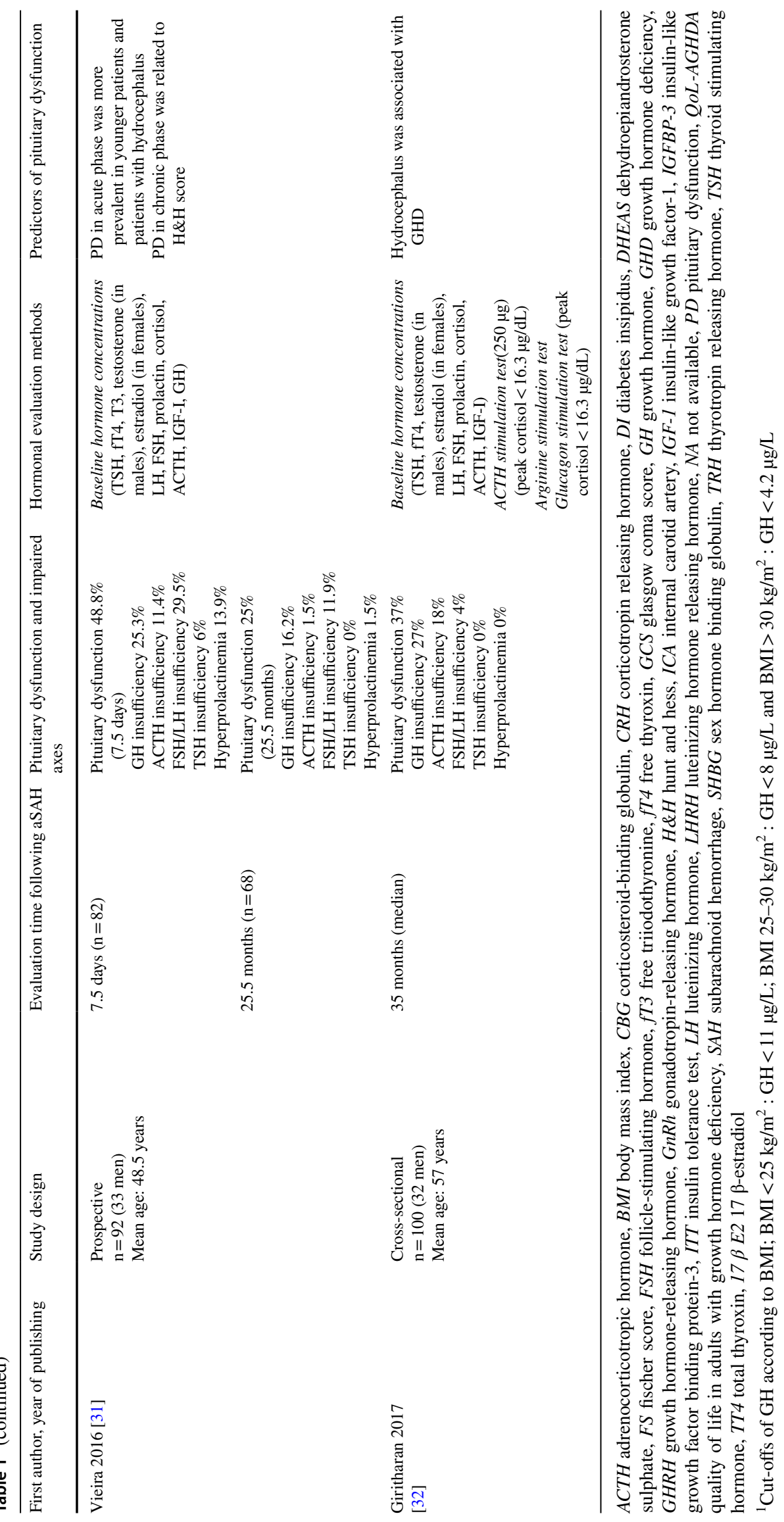




\section{Pathophysiology of neuroendocrine changes and risk factors for aSAH}

The mechanisms underlying the anterior pituitary dysfunction seen after aSAH are still unclear. Although various mechanisms such as direct mechanical trauma to the hypothalamus, pituitary stalk or the pituitary gland, vascular/ hypoxic insult to the hypothalamus or pituitary gland, inflammatory changes, compression from hemorrhage, edema or increased intracranial pressure, genetic predisposition and autoimmunity have been suggested for traumatic brain injuries (TBI) [38], much less is known for aSAH. The pathogenesis of aSAH induced hypopituitarism relates to the proximity of the circle of Willis to the hypothalamic-pituitary complex. Direct compression of the pituitary by the aneurysm itself (Fig. 1), ischemic injury in the very acute phase, increased intracranial pressure or surgical procedure related injuries or drugs have been suggested to alter pituitary functions after aSAH [14].

The high prevalence of abnormal laboratory values in the acute phase of aSAH may be physiological adaptation to critical illness [30]. However ongoing neuroendocrine changes seen later are probably due to ischemia induced damage. The unique portal system of the hypothalamohypophyseal unit makes it vulnerable to ischemia induced damage. The somatotroph cells are located in the lateral wings of pituitary and gonadotroph cells are scattered throughout pars distalis. They receive their blood supply from the long hypophyseal portal vessels. So these cells are more vulnerable to ischemia induced damage [39] explaining the higher frequency of GHD in these

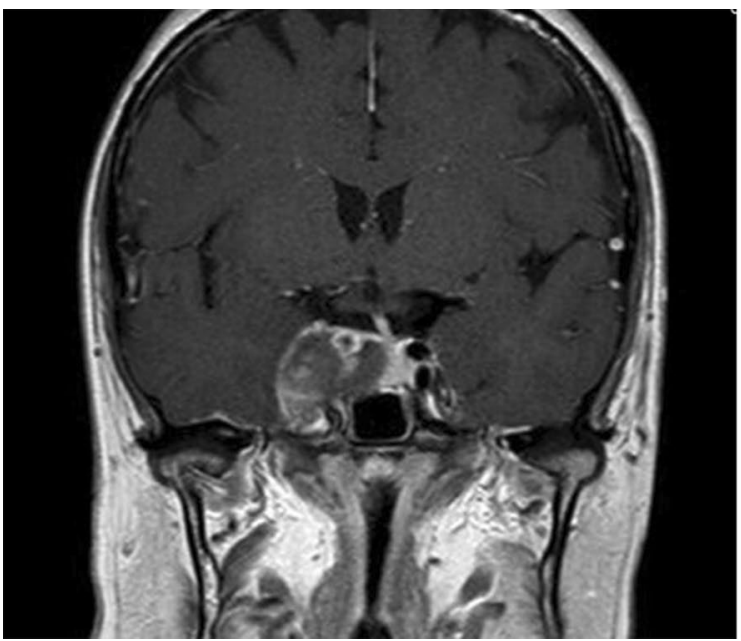

Fig. 1 Pituitary MRI images of a 60 year-old female patient. A large $(3 \times 2 \times 2 \mathrm{~cm})$ mass lesion had iso- and hyperintense areas on T1-weighted and iso- and hypointense areas on T2-weighted images. Aneurysmatic rupture obliterated right cavernous sinus and caused patients. Corticotrophs, located in the central wedge and pars intermedia, and the thyrotrophs, tending to cluster in the anteromedial portion of the gland, are thus in the less susceptible short hypophyseal portal territory.

Autopsy findings demonstrated ischemic necrosis, microand macrohemorrages in the hypothalamus of 68 of 102 patients with SAH [40]. Hypothalamic microhemorhages were found to be localized to paraventricular and supraoptic nuclei which was postulated to be a result of temporary obstruction of venous drainage in these nuclei due to increased pressure in the chiasmatic cistern after the hemorrhage. Direct damage of fine perforating hypothalamic arteries, ischemia due to vasoconstriction, subarachnoid blood forced up the sheaths of the perforating arteries and then rupturing out into the cerebral parenchyma were other suggested possible mechanisms [40]. Extravasated blood triggers a proinflammatory cascade which lead to various complications of aSAH besides its physical damage [41].

The discordance in the frequency of HPA axis dysfunction in TBI and SAH may be explained by a hypothalamic (rather than pituitary) dysfunction in SAH.

Studies have also looked for possible risk factors for hypopituitarism after aSAH. Age of the patient was shown to be significantly related to the prevalence of pituitary dysfunction in the acute phase [6]. The prevalence of pituitary dysfunction was found to be decreased by $2 \%$ for each increasing year of the patient [6]. These findings are in contrast to the results by Tanriverdi et al. that showed increasing age is associated with hypopituitarism in the acute phase [3]. In the follow up, a significant association between younger age and pituitary dysfunction was reported by Kronvall et al. [27].

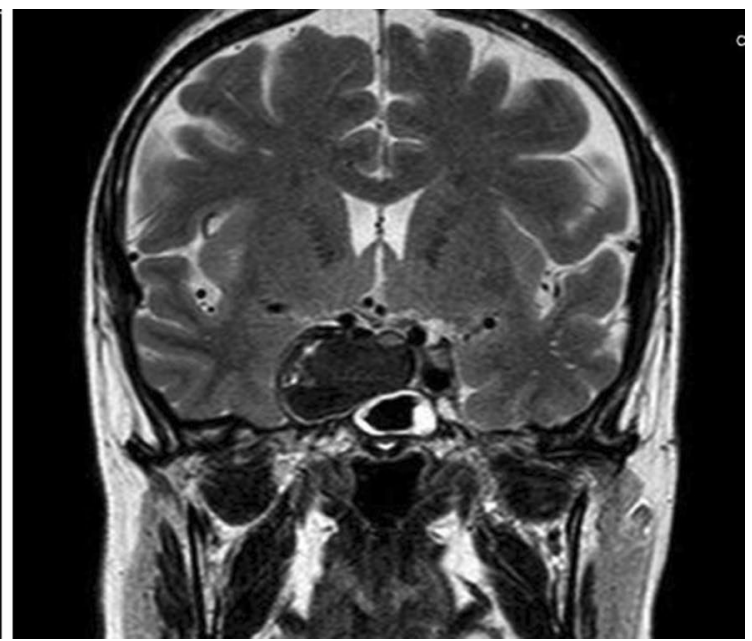

compression of the pituitary gland. She was admitted to the emergency department with the complaints of nausea, vomiting and diplopia. On physical exam she had cranial nerve 3, 4 and 6 palsies 
Surgical clipping of the aneurysm has been shown to increase the risk of hypopituitarism. So surgical procedures may also be important in the development of hypopituitarism. However gender, systemic diseases such as diabetes and hypertension, smoking, Fisher and Hunt Hess score, location of the aneurysm were not found to influence the prevalence in the acute or chronic phase [6]. Goto et al. found GHD in five patients with aSAH who had a location of the aneurysm in the anterior cerebral and internal carotid artery [29]. However the number of patients is limited to make inferences.

Clinical severity of aSAH does not help to discriminate patients at high or low risk of developing hypopituitarism unlike TBI [12]. Inconsistent results are reported regarding predictive factors for hypopituitarism after aSAH. Female sex for ACTH deficiency [36], presence of cerebral vasospasm or hydrocephalus for hypopituitarism [10, 16] have been reported as possible risk factors. But the studies have different designs and not all parameters, that could be related to pituitary dysfunction after aSAH, are reported in the literature.

\section{Impact of neuroendocrine changes on outcome of the patient}

Hypocortisolemia in the acute phase of aSAH may lead to immediate complications and excess mortality. Weant et al. reported a subgroup of patients with relative adrenal insufficiency requiring hormonal replacement therapy with hydrocortisone to assist with inducing therapeutic hypertensive therapy [15]. Lack of dynamic endocrine testing in the acute phase of aSAH and exclusion of patients with poor neurological outcome after aSAH in prospective trials makes it difficult to ascertain the issue of HPA axis dysfunction [42]. Poll et al. has found that patients with normal diurnal serum free cortisol measurement had a significantly shorter intensive care unit-stay, less complications and more favorable outcome [18] (Table 2). However, the empirical glucocorticoid replacement which is not based on the presence of documented acute HPA axis dysfunction may be harmful or, at best, ineffective [43].

Some authors reported a significant association between pituitary dysfunction and patient outcome [17, 23]. Lammert et al. has shown that all patients with neuroendocrine dysfunction had impaired clinical outcome [20]. However, the prevalence of pituitary dysfunction was not found to be associated with the outcome of the patient in other studies $[6,12,24]$.

Kreitchmann-Andermahr et al. demonstrated that endocrine disturbances contribute to the disturbed quality of life, depression and sleeping disturbances. Low basal cortisol level was associated with low quality of life scores and high depression scores. Severe GHD was associated with low scores of energy, quality of life, increased body mass index and waist hip ratio, and possibly associated with glasgow outcome scale (GOS) [32, 45]. A cross sectional study of 34 patients with TBI or aSAH demonstrated a relation between pituitary dysfunction and diminished functional performance 5-12 months after the event [11]. However this association was not adjusted for severity of TBI or aSAH. A prospective cohort in 51 aSAH patients reported an association between pituitary dysfunction and GOS score [26].

Further research is needed to understand the consequences of neuroendocrine changes on neurocognitive, emotional, and quality of life parameters. Correction of detected hormone deficiencies may favorably impact the outcome of patients with aSAH.

\section{Diagnosis}

Timing of assessment of pituitary function is an important factor affecting the prevalence of pituitary dysfunction [46]. An early assessment, particularly the first 3-6 months after the event, may lead to overestimation of pituitary dysfunction.

Diagnosis of adrenal insufficiency during the acute phase of aSAH is critical since it can be life threatening. Patients should be evaluated for signs and symptoms of hypocortisolism including hyponatremia, hypotension, and hypoglycemia. Morning serum cortisol level should be checked in the first days after aSAH [47]. Serum total cortisol values can be influenced by several factors including the degree of severity of the underlying illness, sepsis, and medications making it difficult to define a cortisol cut-off that will help diagnose adrenal failure in acute illness. Acute phase morning cortisol level of less than $7.2 \mu \mathrm{g} / \mathrm{dL}(200 \mathrm{nmol} / \mathrm{L})$ may be suggestive of adrenal insufficiency in acutely ill patients with aSAH, and glucocorticoid replacement should be instituted. Morning cortisol level between 7.2 and $18 \mu \mathrm{g} / \mathrm{dL}$ (200-500 nmol/L) in the presence of features suggestive of adrenal insufficiency such as hyponatremia, hypoglycemia, hypotension, or unexpected slow recovery may still be inappropriately low and a trial of glucocorticoid therapy should be considered [12].

Due to lack of evidence for improved outcome by the treatment of GH, gonadotropin and TSH insufficiencies in the acute phase of aSAH, assessment of these axes is currently not recommended. Furthermore, the physiological response to acute and critical illness comprises hormonal changes similar to GHD, central hypogonadism and hypothyroidism.

Currently, no neurological or clinical parameters exist to accurately predict the presence of hypopituitarism after aSAH [34]. Between 3 and 6 months after injury, clinical 


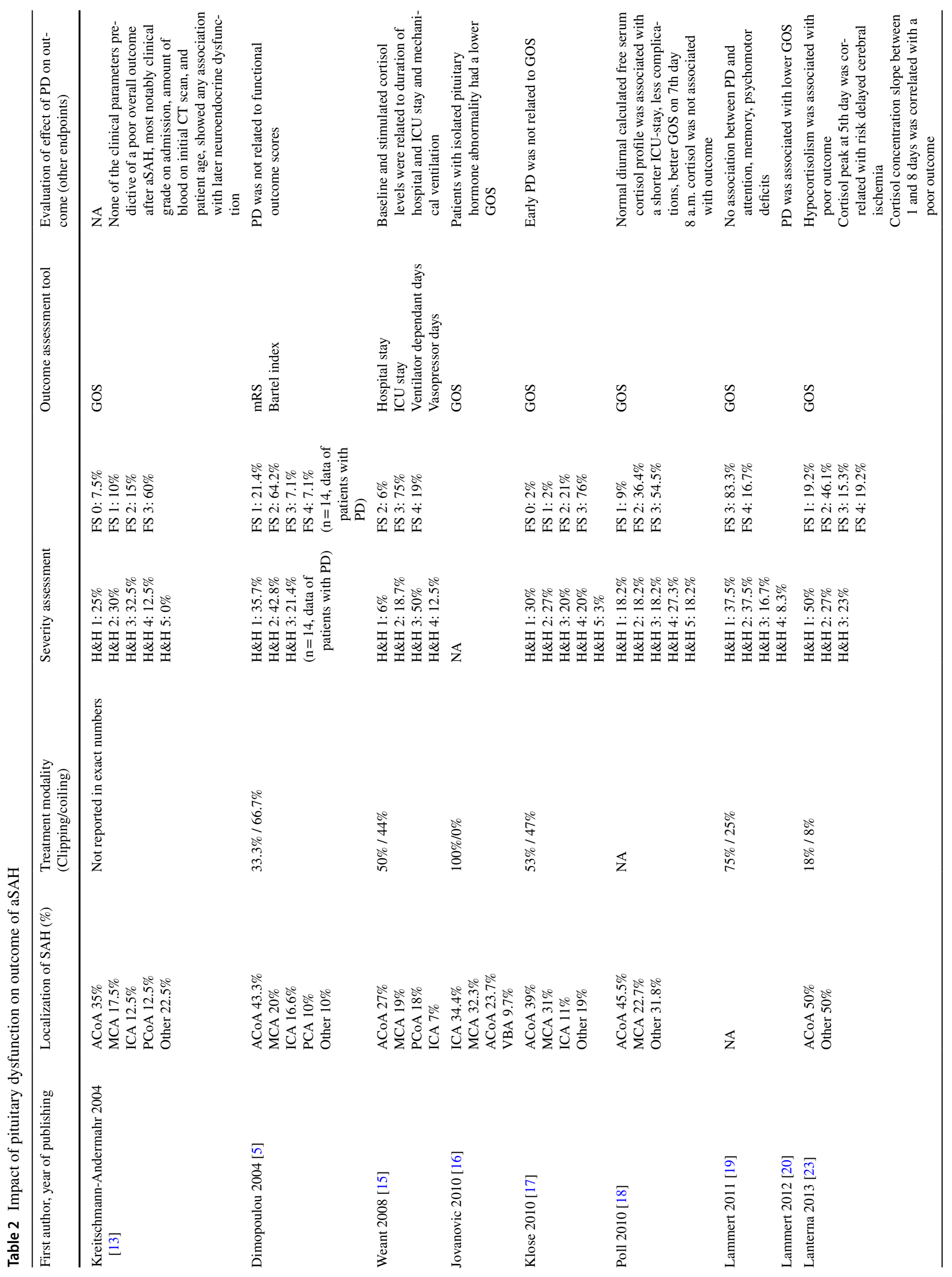




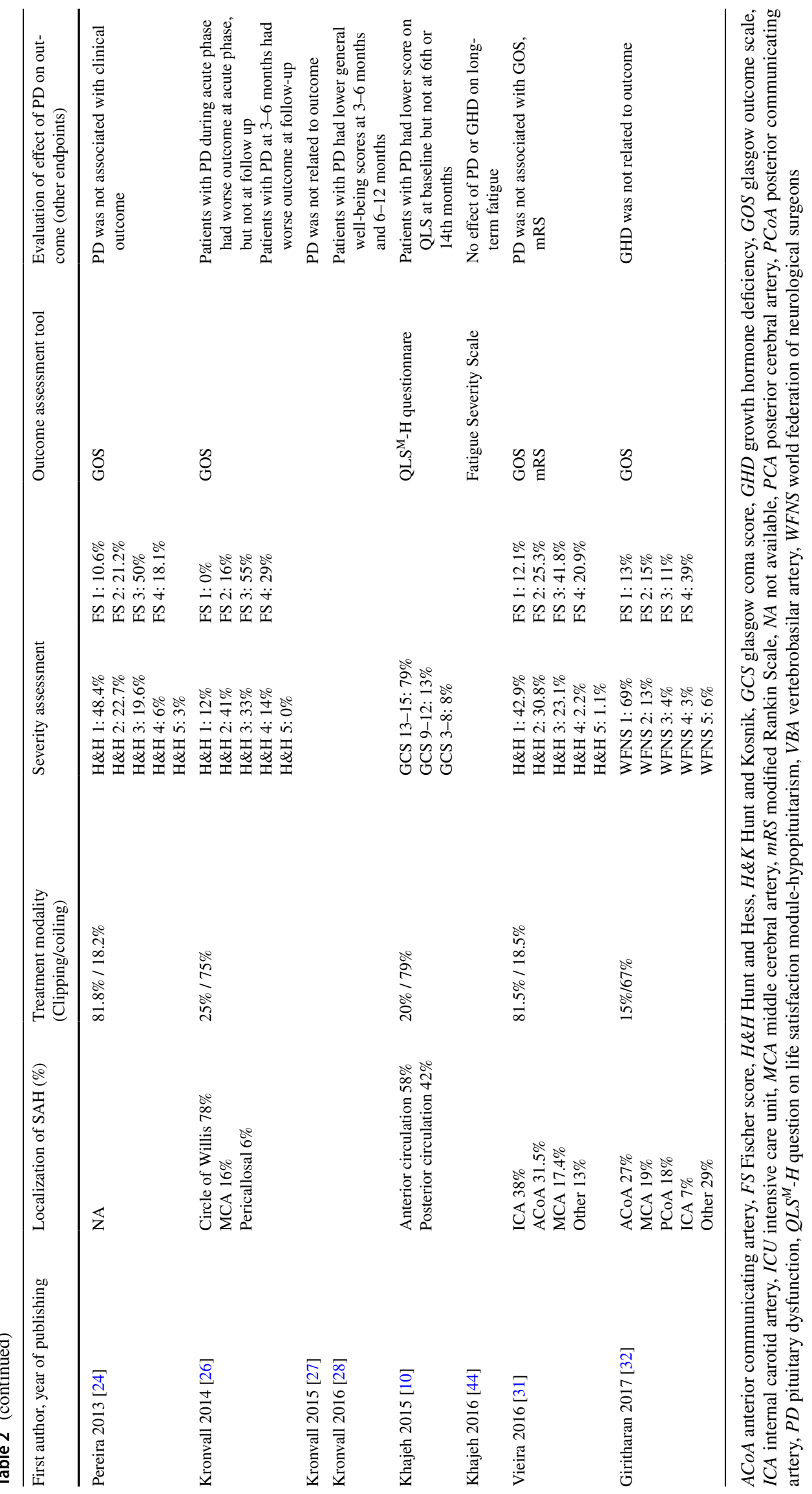


signs of hypopituitarism should be checked paying particular attention to loss of secondary hair, new oligomenorrhea/ amenorrhea, impaired sexual function, weight changes, polydipsia, hyponatremia, hypotension, hypoglycemia or poor recovery. Pituitary assessment should be performed in the presence of these findings. However, the sequelae of brain injury may mask the signs of hypopituitarism, therefore in cases of uncertainty, hormonal assessment should be performed at least once [48].

After 3-6 months, an endocrine assessment with basal hormone levels should be carried out. For HPA axis, a basal cortisol level $>18 \mu \mathrm{g} / \mathrm{dL}$ is accepted as normal and $<3 \mu \mathrm{g} /$ $\mathrm{dL}$ as abnormal. Between these levels dynamic assessment is required. Low dose $(1 \mu \mathrm{g}) \mathrm{ACTH}$ test is a sensitive test and a peak cortisol level $<18 \mu \mathrm{g} / \mathrm{dL}$ is accepted as insufficient [46]. However, we have previously shown that the peak cortisol response can be as low as $12.5 \mu \mathrm{g} / \mathrm{dL}$ in healthy individuals [49]. If high dose $(250 \mu \mathrm{g}) \mathrm{ACTH}$ test is used, a peak cortisol level $<18 \mu \mathrm{g} / \mathrm{dL}$ is accepted as insufficient. Glucagon stimulation test and ITT [23] have the advantage of evaluating both HPA and GH axes. Although ITT is accepted as the gold standard test, patients with aSAH may have epilepsy or at least may be prone to epilepsy which makes ITT contraindicated or relatively contraindicated for them. A peak cortisol response $<18 \mu \mathrm{g} / \mathrm{dL}$ is accepted as insufficient during ITT, however recent findings suggested lower cut-off levels for ITT to prevent overestimation of adrenal insufficiency [50,51]. Glucagon is relatively a weak stimulant for HPA axis and a cortisol response $<10 \mu \mathrm{g} / \mathrm{dL}$ can be accepted as insufficient [52].

A combination of free T4 and TSH level is adequate for the evaluation of integrity of thyroid axis. A low free T4 in the presence of inappropriately normal or low TSH should be accepted as secondary hypothyroidism.

Symptoms and signs of hypogonadism are important in the assessment of gonadal axis. In a woman with past history of aSAH, if menstrual cycle is normal, no hormonal tests are needed. In post menopausal women and premenopausal women with menstrual irregularities low estradiol levels; and in men, repeatedly low testosterone levels in the presence of low or inappropriately normal gonadotropin levels (after exclusion of hyperprolactinemia) indicate secondary hypogonadism.

If all other pituitary axes are normal, a normal IGF-1 level according to age and sex reference is sufficient for the exclusion of GHD. If patient has panhypopituitarism and low IGF-1 level, GHD can be diagnosed. However, if IGF-1 level is low and other pituitary axes are normal, or IGF-1 is normal in the presence of other accompanying hormone deficiencies, then dynamic testing is required. Growth hormone testing should be performed after appropriate replacement of glucocorticoid and L-thyroxine. Insulin tolerance test, GST, GHRH-arginine or GHRH-GHRP-6 tests can be used. A peak GH level $\leq 3 \mu \mathrm{g} / \mathrm{L}$ during ITT or $\leq 1.1 \mu \mathrm{g} / \mathrm{L}$ during GST are accepted as GHD [3]. GHRH-arginine or GHRH-GHRP-6 tests body mass index specific cut-offs are suggested to be used [46]. However, GHRH and GHRP-6 are unavailable.

Reassessment of pituitary functions 1 year after aSAH would be appropriate in order to determine potential recovery and less commonly new-onset deficiencies [14, 20, 22, $27,34,42]$. However, a laboratory value below a defined cut-off level may not necessarily reflect a clinically relevant hormone deficiency.

\section{Treatment}

The nonspecifity of the symptoms of hypopituitarism necessitate a through correlation with the degree of abnormalities in hormonal tests. Detection of adrenal insufficiency in the acute aSAH setting should be promptly treated as it may impact early outcome. In the subsequent months after aSAH, hormonal evaluation is recommended but treatment should be individualized. Treatments of hypocortisolemia and hypothyroidism are essential since these hormones are required for stress adaptation, cardiovascular and metabolic regulation.

On the other hand, gonadotropin deficiency seems to be transient in the acute phase and there is no clear evidence for the replacement of sex steroids in the acute phase of aSAH. Kopczak et al. gave testosterone replacement to 13 patients with low testosterone levels in a neurorehabilitaion unit about 1 month after the event. Four patients showed a $\mathrm{Hb}$ increase of $>2 \mathrm{~g} / \mathrm{dL}$, and 5 of them showed improvement of Barthel index $>20$ points indicating possible benefits [30]. Randomized placebo controlled trials are necessary to further investigate the effect of hormonal suppletion after acute brain injury. If hypogonadism persists in the chronic phase, sex steroid replacement should be done as in other causes of hypogonadism. Treatment of GHD should be individualized according to symptoms, age and underlying disorders of the patient.

\section{Posterior pituitary dysfunction}

Posterior hypopituitarism leads to central diabetes insipidus (DI) and rarely potentially life threatening hypernatremia when associated with impaired thirst sensation or inadequate fluid intake. Aimeretti et al. reported 2.8\% of DI in $32 \mathrm{SAH}$ survivors after 12 months [14]. Diabetes insipidus was seen in $15 \%$ of cases after aSAH in the acute setting, which was associated with poorer patient outcome [53]. Adipsic DI has occasionally been reported after aSAH, in particular after clipping of anterior communicating artery aneurysms 
[54-56], which is usually permenant and such patients are candidates for developing other hypothalamic abnormalities such as obesity and obstructive sleep apnea syndrome [57]. Diabetes insipidus in this situation was speculated to be a manifestation of acute elevation in intracranial pressure. The osmoreceptors receive their blood supply from small arteries arising from the anterior communicating artery and these vessels are assumed to be damaged during aneurysm clipping, with infarction of the circumventricular organs where the osmoreceptors are sited [58]. Patients with DI are treated with desmopressin by a dose proportional to the degree of DI. A dose per week can be skipped in order to prevent the development of iatrogenic hyponatremia. Patients with adipsic DI are required to be managed by a combination of regular desmopressin and fixed fluid intake, with regular measurements of plasma sodium concentration [59].

Hyponatremia is very common after aSAH seen in $30 \%$ of patients $[53,60]$. Mild hyponatremia $(\mathrm{Na}<135 \mathrm{mmol} / \mathrm{L})$ was detected in $57 \%$, moderate-severe hyponatremia $(\mathrm{Na}<130 \mathrm{mmol} / \mathrm{L})$ in $20 \%$ of 316 aSAH patients in a retrospective study [61] and the high rate of hyponatremia $(50 \%$ of patients $<135 \mathrm{mmol} / \mathrm{L}$ ) was confirmed in a later prospective study [62]. The most common cause for hyponatremia was syndrome of inappropriate antidiuretic hormone secretion (62-72\% of cases) and hyponatremia was associated with longer hospital stay but not with mortality [61, 62]. Hyponatremia was not found to be associated with any particular site of aneurysm or method of aneurysm management $[61,62]$. See et al. demonstrated an association of old age with hyponatremia and smoking habit with longer duration of hyponatremia [63]. Diabetes insipidus is usually transient after aSAH in majority of cases [14], but sometimes persist up to 3 months [9].

Nevertheless, hypernatremia may be more predictive for mortality than hyponatremia in patients with aSAH $[59,64$, 65]. On the other hand, correct management of hyponatremia is important since it is responsible for one of six readmissions after hospital discharge of patients with aSAH [66]. A metaanalysis of steroid therapy following aSAH demonstrated lower rates of hyponatremia with fludrocortisone or hydrocortisone supplementation [67]. The cause of hyponatremia and the velocity of development are important for the management. If hyponatremia develops over several days, brain adaptation occurs which prevents development of cerebral edema. In case of acute hyponatremia cerebral edema may develop so it should be corrected promptly and effectively. Initial correction of 3-5 mmol/L over $2-4 \mathrm{~h}$ is essential to reduce cerebral edema [68]. For severe symptoms, $100 \mathrm{~mL}$ of $3 \%$ saline over $10 \mathrm{~min}$ can be given and repeated 3 times until clinical improvement and then the targeted $\mathrm{Na}$ level can be reached in the next $24 \mathrm{~h}$. For milder symptoms, $3 \%$ saline infusion rate can be $0.5-2 \mathrm{~mL} / \mathrm{kg} / \mathrm{h}$. Plasma $\mathrm{Na}$ rise should be $<8 \mathrm{mmol} / 24 \mathrm{~h}$ and should not exceed $12 \mathrm{mmol} / 24 \mathrm{~h}$ in order to prevent osmotic demyelination [59].

\section{Conclusion}

Hypopituitarism seems to be a common complication of aSAH. The course of hypopituitarism may be dynamic with recovery and deterioration of hormone deficiencies in the follow up. In the immediate period after aneurysm rupture, ACTH deficiency and disorders of water balance have the priority of detection after aSAH. The reported prevalence rates vary considerably due to different dynamic tests and cut-offs used in the studies. Screening for hypopituitarism after aSAH should be carried out despite lack of gold standard evaluation tests and cut-off values in the follow up, because missed diagnosis may lead to untoward consequences. However, a laboratory value below a defined cut-off level may not necessarily reflect a clinically relevant hormone deficiency.

\section{Compliance with ethical standards}

Conflict of interest Zuleyha Karaca, Aysa Hacioglu, Fahrettin Kelestimur declares that they have no conflict of interest.

Ethical approval This article does not contain any studies with human participants or animals performed by any of the authors.

Informed consent Informed consent was obtained from the only patient whose MR imaging was included in the review.

\section{References}

1. van Gijn J, Kerr RS, Rinkel GJ (2007) Subarachnoid haemorrhage. Lancet 369(9558):306-318. https://doi.org/10.1016/S0140 -6736(07)60153-6

2. Long B, Koyfman A, Runyon MS (2017) Subarachnoid hemorrhage: updates in diagnosis and management. Emerg Med Clin N Am 35(4):803-824. https://doi.org/10.1016/j.emc.2017.07.001

3. Tanriverdi F, Ulutabanca H, Unluhizarci K, Selcuklu A, Casanueva FF, Kelestimur F (2008) Three years prospective investigation of anterior pituitary function after traumatic brain injury: a pilot study. Clin Endocrinol (Oxf) 68(4):573-579. https://doi.org /10.1111/j.1365-2265.2007.03070.x

4. Bendel S, Koivisto T, Ruokonen E, Rinne J, Romppanen J, Vauhkonen I, Kiviniemi V, Uusaro A (2008) Pituitary-adrenal function in patients with acute subarachnoid haemorrhage: a prospective cohort study. Crit Care 12(5):R126. https://doi. org/10.1186/cc7084

5. Dimopoulou I, Kouyialis AT, Tzanella M, Armaganidis A, Thalassinos N, Sakas DE, Tsagarakis S (2004) High incidence of neuroendocrine dysfunction in long-term survivors of aneurysmal subarachnoid hemorrhage. Stroke 35(12):2884-2889. https://doi. org/10.1161/01.STR.0000147716.45571.45 
6. Robba C, Bacigaluppi S, Bragazzi N, Lavinio A, Gurnell M, Bilotta F, Menon DK (2016) Clinical prevalence and outcome impact of pituitary dysfunction after aneurysmal subarachnoid hemorrhage: a systematic review with meta-analysis. Pituitary 19(5):522-535. https://doi.org/10.1007/s11102-016-0733-2

7. Hoff WV, Hornabrook RW, Marks V (1961) Hypopituitarism associated with intracranial aneurysms. Br Med J 2(5261):1190-1194

8. Jenkins JS, Buckell M, Carter AB, Westlake S (1969) Hypothalamic-pituitary-adrenal function after subarachnoid haemorrhage. Br Med J 4(5685):707-709

9. Aimaretti G, Ambrosio MR, Di Somma C, Fusco A, Cannavo S, Gasperi M, Scaroni C, De Marinis L, Benvenga S, degli Uberti EC, Lombardi G, Mantero F, Martino E, Giordano G, Ghigo E (2004) Traumatic brain injury and subarachnoid haemorrhage are conditions at high risk for hypopituitarism: screening study at 3 months after the brain injury. Clin Endocrinol (Oxf) 61(3):320 326. https://doi.org/10.1111/j.1365-2265.2004.02094.x

10. Khajeh L, Blijdorp K, Heijenbrok-Kal MH, Sneekes EM, van den Berg-Emons HJ, van der Lely AJ, Dippel DW, Neggers SJ, Ribbers GM, van Kooten F (2015) Pituitary dysfunction after aneurysmal subarachnoid haemorrhage: course and clinical predictorsthe HIPS study. J Neurol Neurosurg Psychiatry 86(8):905-910. https://doi.org/10.1136/jnnp-2014-307897

11. Srinivasan L, Roberts B, Bushnik T, Englander J, Spain DA, Steinberg GK, Ren L, Sandel ME, Al-Lawati Z, Teraoka J, Hoffman AR, Katznelson L (2009) The impact of hypopituitarism on function and performance in subjects with recent history of traumatic brain injury and aneurysmal subarachnoid haemorrhage. Brain Inj 23(7):639-648. https://doi.org/10.1080/0269905090 2970778

12. Schneider HJ, Kreitschmann-Andermahr I, Ghigo E, Stalla GK, Agha A (2007) Hypothalamopituitary dysfunction following traumatic brain injury and aneurysmal subarachnoid hemorrhage: a systematic review. JAMA 298(12):1429-1438. https:// doi.org/10.1001/jama.298.12.1429

13. Kreitschmann-Andermahr I, Hoff C, Saller B, Niggemeier S, Pruemper S, Hutter BO, Rohde V, Gressner A, Matern S, Gilsbach JM (2004) Prevalence of pituitary deficiency in patients after aneurysmal subarachnoid hemorrhage. J Clin Endocrinol Metab 89(10):4986-4992. https://doi.org/10.1210/jc.2004-0146

14. Aimaretti G, Ambrosio MR, Di Somma C, Gasperi M, Cannavo S, Scaroni C, Fusco A, Del Monte P, De Menis E, Faustini-Fustini M, Grimaldi F, Logoluso F, Razzore P, Rovere S, Benvenga S, Degli Uberti EC, De Marinis L, Lombardi G, Mantero F, Martino F, Giordano G, Ghigo E (2005) Residual pituitary function after brain injury-induced hypopituitarism: a prospective 12-month study. J Clin Endocrinol Metab 90(11):6085-6092. https://doi. org/10.1210/jc.2005-0504

15. Weant KA, Sasaki-Adams D, Dziedzic K, Ewend M (2008) Acute relative adrenal insufficiency after aneurysmal subarachnoid hemorrhage. Neurosurgery 63(4):645-649. https://doi.org/10.1227/01. NEU.0000325728.50939.15 (discussion 649-650 )

16. Jovanovic V, Pekic S, Stojanovic M, Tasic G, Djurovic B, Soldatovic I, Doknic M, Miljic D, Djurovic M, Medic-Stojanoska M, Popovic V (2010) Neuroendocrine dysfunction in patients recovering from subarachnoid hemorrhage. Hormones (Athens) 9(3):235-244

17. Klose M, Brennum J, Poulsgaard L, Kosteljanetz M, Wagner A, Feldt-Rasmussen U (2010) Hypopituitarism is uncommon after aneurysmal subarachnoid haemorrhage. Clin Endocrinol (Oxf) 73(1):95-101. https://doi.org/10.1111/j.1365-2265.2010.03791.x

18. Poll EM, Bostrom A, Burgel U, Reinges MH, Hans FJ, Gilsbach JM, Kreitschmann-Andermahr I (2010) Cortisol dynamics in the acute phase of aneurysmal subarachnoid hemorrhage: associations with disease severity and outcome. J Neurotrauma 27(1):189-195. https://doi.org/10.1089/neu.2009.1014

19. Lammert A, Bode H, Hammes HP, Birck R, Fatar M, Zohsel K, Braun J, Schmieder K, Diepers M, Schubert GA, Barth M, Thome C, Seiz M (2011) Neuro-endocrine and neuropsychological outcome after aneurysmal subarachnoid hemorrhage (aSAH): a prospective cohort study. Exp Clin Endocrinol Diabetes 119(2):111116. https://doi.org/10.1055/s-0030-1262815

20. Lammert A, Bode H, Hammes HP, Birck R, Fatar M, Zohsel K, Schmieder K, Schubert GA, Thome C, Seiz M (2012) Aneurysmal subarachnoid hemorrhage (aSAH) results in low prevalence of neuro-endocrine dysfunction and NOT deficiency. Pituitary 15(4):505-512. https://doi.org/10.1007/s11102-011-0357-5

21. Dutta P, Mukherjee KK, Chaudhary PK, Masoodi SR, Anand S, Pathak A, Shah VN, Mathuriya SN (2012) Pituitary dysfunction in survivors of spontaneous subarachnoid hemorrhage of anterior communicating artery and middle cerebral artery aneurysms: A comparative study. Neurol India 60(4):390-394

22. Karaca Z, Tanriverdi F, Dagli AT, Selcuklu A, Casanueva FF, Unluhizarci K, Kelestimur F (2013) Three years prospective investigation of pituitary functions following subarachnoid haemorrhage. Pituitary 16(1):76-82. https://doi.org/10.1007/s1110 2-012-0377-9

23. Lanterna LA, Spreafico V, Gritti P, Prodam F, Signorelli A, Biroli F, Aimaretti G (2013) Hypocortisolism in noncomatose patients during the acute phase of subarachnoid hemorrhage. J Stroke Cerebrovasc Dis 22(7):e189-e196. https://doi.org/10.1016/j.jstro kecerebrovasdis.2012.11.002

24. Pereira JL, Albuquerque LA, Dellaretti M, Carvalho GT, Vieira G Jr, Brochado VM, Drummond AV, Morais JE, Ferreira LM, Miranda PA, Sousa AA (2013) Pituitary deficiency after aneurysmal subarachnoid hemorrhage. Clinics (Sao Paulo) 68(6):745749. https://doi.org/10.6061/clinics/2013(06)04

25. Kopczak A, Kilimann I, von Rosen F, Krewer C, Schneider HJ, Stalla GK, Schneider M (2014) Screening for hypopituitarism in 509 patients with traumatic brain injury or subarachnoid hemorrhage. J Neurotrauma 31(1):99-107. https://doi.org/10.1089/ neu. 2013.3002

26. Kronvall E, Valdemarsson S, Saveland H, Nilsson OG (2014) Pituitary dysfunction after aneurysmal subarachnoid hemorrhage is associated with impaired early outcome. World Neurosurg 81(3-4):529-537. https://doi.org/10.1016/j.wneu.2013.10.038

27. Kronvall E, Valdemarsson S, Saveland H, Nilsson OG (2015) High prevalence of pituitary dysfunction after aneurysmal subarachnoid hemorrhage: a long-term prospective study using dynamic endocrine testing. World Neurosurg 83(4):574-582. https ://doi.org/10.1016/j.wneu.2014.12.007

28. Kronvall E, Sonesson B, Valdemarsson S, Siemund R, Saveland H, Nilsson OG (2016) Reduced quality of life in patients with pituitary dysfunction after aneurysmal subarachnoid hemorrhage: a prospective longitudinal study. World Neurosurg 88:83-91. https ://doi.org/10.1016/j.wneu.2015.12.057

29. Goto Y, Oshino S, Nishino A, Fujinaka T, Nakamura H, Yuguchi T, Mori S, Yoshimine T, Saitoh Y (2016) Pituitary dysfunction after aneurysmal subarachnoid hemorrhage in Japanese patients. J Clin Neurosci 34:198-201. https://doi.org/10.1016/j. jocn.2016.07.003

30. Krewer C, Schneider M, Schneider HJ, Kreitschmann-Andermahr I, Buchfelder M, Faust M, Berg C, Wallaschofski H, Renner C, Uhl E, Koenig E, Jordan M, Stalla GK, Kopczak A (2016) Neuroendocrine disturbances one to five or more years after traumatic brain injury and aneurysmal subarachnoid hemorrhage: data from the German database on hypopituitarism. J Neurotrauma 33(16):1544-1553. https://doi.org/10.1089/neu.2015.4109

31. Vieira G Jr, de Albuquerque LA, de Avellar AB, Pereira JL, Dellaretti M, Miranda PA, Macedo RA, da Silva LA, Gusmao 
SN (2016) Long-term follow-up of anterior pituitary deficiency after aneurysmal subarachnoid hemorrhage: prospective cohort. J Stroke Cerebrovasc Dis 25(10):2405-2414. https://doi. org/10.1016/j.jstrokecerebrovasdis.2016.06.011

32. Giritharan S, Cox J, Heal CJ, Hughes D, Gnanalingham K, Kearney T (2017) The prevalence of growth hormone deficiency in survivors of subarachnoid haemorrhage: results from a large single centre study. Pituitary 20(6):624-634. https://doi. org/10.1007/s11102-017-0825-7

33. Can A, Gross BA, Smith TR, Dammers R, Dirven CM, Woodmansee WW, Laws ER, Du R (2016) Pituitary dysfunction after aneurysmal subarachnoid hemorrhage: a systematic review and meta-analysis. Neurosurgery 79(2):253-264. https://doi. org/10.1227/NEU.0000000000001157

34. Khajeh L, Blijdorp K, Neggers SJ, Ribbers GM, Dippel DW, van Kooten F (2014) Hypopituitarism after subarachnoid haemorrhage, do we know enough? BMC Neurol 14:205. https://doi. org/10.1186/s12883-014-0205-0

35. Hannon MJ, Behan LA, O'Brien MM, Tormey W, Javadpour M, Sherlock M, Thompson CJ (2015) Chronic hypopituitarism is uncommon in survivors of aneurysmal subarachnoid haemorrhage. Clin Endocrinol (Oxf) 82(1):115-121. https://doi. org/10.1111/cen.12533

36. Kreitschmann-Andermahr I, Hartmann Y, Poll E, Schneider HJ, Buchfelder M, Stalla GK (2011) The German database on hypopituitarism after traumatic brain injury and aneurysmal subarachnoid hemorrhage - description, objectives and design. Exp Clin Endocrinol Diabetes 119(1):15-20. https:// doi.org/10.1055/s-0030-1253414

37. Gardner CJ, Javadpour M, Stoneley C, Purthuran M, Biswas S, Daousi C, MacFarlane IA, Cuthbertson DJ (2013) Low prevalence of hypopituitarism after subarachnoid haemorrhage using confirmatory testing and with BMI-specific GH cut-off levels. Eur J Endocrinol 168(4):473-481. https://doi.org/10.1530/ EJE-12-0849

38. Tanriverdi F, Schneider HJ, Aimaretti G, Masel BE, Casanueva FF, Kelestimur F (2015) Pituitary dysfunction after traumatic brain injury: a clinical and pathophysiological approach. Endocr Rev 36(3):305-342. https://doi.org/10.1210/er.2014-1065

39. Karaca Z, Tanriverdi F, Unluhizarci K, Kelestimur F (2016) GH and pituitary hormone alterations after traumatic brain injury. Prog Mol Biol Transl Sci 138:167-191. https://doi.org/10.1016/ bs.pmbts.2015.10.010

40. Crompton MR (1963) Hypothalamic lesions following the rupture of cerebral berry aneurysms. Brain 86:301-314

41. Sercombe R, Sercombe C, Oudart N, Seylaz J (2002) Critical role of endothelial nitric oxide synthase and cyclooxygenase in response of rabbit basilar artery to serotonin. Jpn J Pharmacol 90(1):67-76

42. Ioachimescu AG, Barrow DL (2015) Subarachnoid Hemorrhage and the Pituitary. World Neurosurg 83(6):1026-1028. https://doi. org/10.1016/j.wneu.2015.01.044

43. Vespa P, Participants in the International Multi-Disciplinary Consensus Conference on the Critical Care Management of Subarachnoid, H.: SAH pituitary adrenal dysfunction. Neurocrit Care 15(2), 365-368 (2011). https://doi.org/10.1007/s1202 8-011-9595-7

44. Khajeh L, Ribbers GM, Heijenbrok-Kal MH, Blijdorp K, Dippel DW, Sneekes EM, van den Berg-Emons HJ, van der Lely AJ, Neggers SJ, van Kooten F (2016) The effect of hypopituitarism on fatigue after subarachnoid hemorrhage. Eur J Neurol 23(8):12691274. https://doi.org/10.1111/ene.13014

45. Kreitschmann-Andermahr I, Poll E, Hutter BO, Reineke A, Kristes S, Gilsbach JM, Saller B (2007) Quality of life and psychiatric sequelae following aneurysmal subarachnoid haemorrhage: does neuroendocrine dysfunction play a role? Clin Endocrinol (Oxf)
66(6):833-837. https://doi.org/10.1111/j.1365-2265.2007.02821 . $\mathrm{x}$

46. Karamouzis I, Pagano L, Prodam F, Mele C, Zavattaro M, Busti A, Marzullo P, Aimaretti G (2016) Clinical and diagnostic approach to patients with hypopituitarism due to traumatic brain injury (TBI), subarachnoid hemorrhage (SAH), and ischemic stroke (IS). Endocrine 52(3):441-450. https://doi.org/10.1007/s1202 0-015-0796-2

47. Cohan P, Wang C, McArthur DL, Cook SW, Dusick JR, Armin B, Swerdloff R, Vespa P, Muizelaar JP, Cryer HG, Christenson PD, Kelly DF (2005) Acute secondary adrenal insufficiency after traumatic brain injury: a prospective study. Crit Care Med 33(10):2358-2366

48. Brandt L, Saveland H, Valdemarsson S, Sjoholm H, Reinstrup P (2004) Fatigue after aneurysmal subarachnoid hemorrhage evaluated by pituitary function and 3D-CBF. Acta Neurol Scand 109(2):91-96

49. Karaca Z, Lale A, Tanriverdi F, Kula M, Unluhizarci K, Kelestimur F (2011) The comparison of low and standard dose ACTH and glucagon stimulation tests in the evaluation of hypothalamo-pituitary-adrenal axis in healthy adults. Pituitary 14(2):134-140. https://doi.org/10.1007/s11102-010-0270-3

50. Simsek Y, Karaca Z, Tanriverdi F, Unluhizarci K, Selcuklu A, Kelestimur F (2015) A comparison of low-dose ACTH, glucagon stimulation and insulin tolerance test in patients with pituitary disorders. Clin Endocrinol (Oxf) 82(1):45-52. https://doi. org/10.1111/cen.12528

51. Cho HY, Kim JH, Kim SW, Shin CS, Park KS, Kim SW, Jang HC, Kim SY (2014) Different cut-off values of the insulin tolerance test, the high-dose short Synacthen test $(250 \mathrm{mug})$ and the low-dose short Synacthen test (1 mug) in assessing central adrenal insufficiency. Clin Endocrinol (Oxf) 81(1):77-84. https://doi. org/10.1111/cen.12397

52. Berg C, Meinel T, Lahner H, Yuece A, Mann K, Petersenn S (2010) Diagnostic utility of the glucagon stimulation test in comparison to the insulin tolerance test in patients following pituitary surgery. Eur J Endocrinol 162(3):477-482. https://doi. org/10.1530/EJE-09-0824

53. Qureshi AI, Suri MF, Sung GY, Straw RN, Yahia AM, Saad M, Guterman LR, Hopkins LN (2002) Prognostic significance of hypernatremia and hyponatremia among patients with aneurysmal subarachnoid hemorrhage. Neurosurgery 50(4):749-755 (discussion 755-746)

54. Robertson GL, Aycinena P, Zerbe RL (1982) Neurogenic disorders of osmoregulation. Am J Med 72(2):339-353

55. McIver B, Connacher A, Whittle I, Baylis P, Thompson C (1991) Adipsic hypothalamic diabetes insipidus after clipping of anterior communicating artery aneurysm. BMJ 303(6815):1465-1467

56. Crowley RK, Sherlock M, Agha A, Smith D, Thompson CJ (2007) Clinical insights into adipsic diabetes insipidus: a large case series. Clin Endocrinol (Oxf) 66(4):475-482. https://doi.org /10.1111/j.1365-2265.2007.02754.x

57. Eisenberg Y, Frohman LA (2016) Adipsic diabetes insipidus: a review. Endocr Pract 22(1):76-83. https://doi.org/10.4158/EP159 40.RA

58. Hannon MJ, Sherlock M, Thompson CJ (2011) Pituitary dysfunction following traumatic brain injury or subarachnoid haemorrhage-in "endocrine management in the intensive care unit". Best Pract Res Clin Endocrinol Metab 25(5):783-798. https://doi. org/10.1016/j.beem.2011.06.001

59. Garrahy A, Sherlock M, Thompson CJ (2017) MANAGEMENT OF ENDOCRINE DISEASE: neuroendocrine surveillance and management of neurosurgical patients. Eur J Endocrinol 176(5):R217-R233. https://doi.org/10.1530/EJE-16-0962 
60. Chen I, Mitchell P (2016) Serum potassium and sodium levels after subarachnoid haemorrhage. Br J Neurosurg 30(5):554-559. https://doi.org/10.1080/02688697.2016.1181151

61. Sherlock M, O'Sullivan E, Agha A, Behan LA, Rawluk D, Brennan P, Tormey W, Thompson CJ (2006) The incidence and pathophysiology of hyponatraemia after subarachnoid haemorrhage. Clin Endocrinol (Oxf) 64(3):250-254. https://doi.org/10.111 $1 /$ j.1365-2265.2006.02432.x

62. Hannon MJ, Behan LA, O'Brien MM, Tormey W, Ball SG, Javadpour M, Sherlock M, Thompson CJ (2014) Hyponatremia following mild/moderate subarachnoid hemorrhage is due to SIAD and glucocorticoid deficiency and not cerebral salt wasting. J Clin Endocrinol Metab 99(1):291-298. https://doi.org/10.1210/ jc.2013-3032

63. See AP, Wu KC, Lai PM, Gross BA, Du R (2016) Risk factors for hyponatremia in aneurysmal subarachnoid hemorrhage. J Clin Neurosci 32:115-118. https://doi.org/10.1016/j.jocn.2016.04.006

64. Alimohamadi M, Saghafinia M, Alikhani F, Danial Z, Shirani M, Amirjamshidi A (2016) Impact of electrolyte imbalances on the outcome of aneurysmal subarachnoid hemorrhage: A prospective study. Asian J Neurosurg 11(1):29-33. https://doi. org/10.4103/1793-5482.154978
65. Mapa B, Taylor BE, Appelboom G, Bruce EM, Claassen J, Connolly ES Jr (2016) Impact of hyponatremia on morbidity, mortality, and complications after aneurysmal subarachnoid hemorrhage: a systematic review. World Neurosurg 85:305-314. https ://doi.org/10.1016/j.wneu.2015.08.054

66. Greenberg JK, Washington CW, Guniganti R, Dacey RG Jr, Derdeyn CP, Zipfel GJ (2016) Causes of 30-day readmission after aneurysmal subarachnoid hemorrhage. J Neurosurg 124(3):743749. https://doi.org/10.3171/2015.2.JNS142771

67. Mistry AM, Mistry EA, Ganesh Kumar N, Froehler MT, Fusco MR, Chitale RV (2016) Corticosteroids in the management of hyponatremia, hypovolemia, and vasospasm in subarachnoid hemorrhage: a meta-analysis. Cerebrovasc Dis 42(3-4):263-271. https ://doi.org/10.1159/000446251

68. Verbalis JG, Goldsmith SR, Greenberg A, Korzelius C, Schrier RW, Sterns RH, Thompson CJ (2013) Diagnosis, evaluation, and treatment of hyponatremia: expert panel recommendations. Am J Med 126(10 Suppl 1):S1-S42. https://doi.org/10.1016/j.amjme d.2013.07.006 